Page 1 of 16

\title{
Evidence of a Sewer Vapor Transport Pathway at the USEPA Vapor Intrusion Research Duplex
}

\author{
Thomas McHugh ${ }^{1 *}$, Lila Beckley ${ }^{2}$, Terry Sullivan ${ }^{3}$, Chris Lutes $^{4}$, Robert Truesdale ${ }^{5}$, Rob \\ Uppencamp $^{6}$, Brian Cosky ${ }^{6}$, John Zimmerman ${ }^{7}$, Brian Schumacher ${ }^{7}$ \\ ${ }^{1}$ GSI Environmental Inc., Houston, Texas, United States \\ ${ }^{2}$ GSI Environmental Inc., Austin, Texas, United States \\ ${ }^{3}$ Brookhaven National Laboratory, Upton, New York, United States \\ ${ }^{4} \mathrm{CH} 2 \mathrm{MHill}$, Inc., Raleigh, North Carolina, United States \\ ${ }^{5}$ RTI International, Research Triangle Park, North Carolina, United States \\ ${ }^{6}$ Arcadis, Indianapolis, Indiana, United States \\ ${ }^{7}$ US Environmental Protection Agency, Las Vegas, Nevada, United States
}

CORRESPONDING AUTHOR: Thomas McHugh, GSI Environmental Inc., 2211 Norfolk, Suite 1000, Houston, Texas 77098, USA, temchugh@gsi-net.com.

\begin{abstract}
The role of sewer lines as preferential pathways for vapor intrusion is poorly understood. Although the importance of sewer lines for volatile organic compound (VOC) transport has been documented at a small number of sites with vapor intrusion, sewer lines are not routinely sampled during most vapor intrusion investigations. We have used a tracer study and VOC concentration measurements to evaluate the role of the combined sanitary / storm sewer line in VOC transport at the USEPA vapor intrusion research duplex in Indianapolis, Indiana. The results from the tracer study demonstrated gas migration from the sewer main line into the duplex. The migration pathway appears to be complex and may include leakage from the sewer lateral at a location below the building foundation. Vapor samples collected from the sewer line demonstrated the presence of tetrachloroethene (PCE) and chloroform in the sewer main in front of the duplex and at multiple sample locations within the sewer line upstream of the duplex. These test results combined with results from the prior multi-year study of the duplex indicate that the sewer line plays an important role in transport of VOCs from the subsurface source to the immediate vicinity of the duplex building envelope.
\end{abstract}

Key Words: preferential pathway, Indianapolis, utility tunnel

\subsection{Introduction}


1

Vapor intrusion is the vapor phase migration of volatile contaminants from a subsurface source into overlying buildings or other structures. Although vapor intrusion has been recognized for decades as a potential exposure pathway, the discovery in the late 1990s of unexpected vapor intrusion exposures at some sites with large groundwater plumes increased the focus on this pathway beginning in the early 2000s (Tillman and Weaver, 2005). Since that time, field investigations, regulatory guidance, and research efforts related to vapor intrusion have greatly increased.

One key challenge for the evaluation of vapor intrusion is high spatial and temporal variability in VOC concentrations within shallow groundwater, soil gas, and indoor air (McHugh et al., 2007). This high variability makes it difficult to evaluate pathway completeness using conventional field investigation methods. In order to better understand the effect of spatial and temporal variability in vapor intrusion, Holton et al., 2013 conducted an intensive multi-year testing program at a single family residence overlying a chlorinated solvent plume in Utah. They found that trichloroethene (TCE) concentrations in indoor air varied by 1000x over time. They found extended periods of no vapor intrusion and shorter periods where vapor intrusion yielded TCE concentrations well above United States Environmental Protection Agency (USEPA) screening values. In addition, unexpected patterns in the distribution of TCE below the residence led to the eventual discovery of a foundation drain system acting as a preferential pathway for TCE migration into the residence (Guo et al., 2015). At this residence, the sub-foundation gravel layer is connected to a neighborhood land drain sewer system. This provides a migration pathway for vapors from the land drain sewer to the sub-slab and then into the residence though a foundation expansion joint and other penetrations.

A preferential pathway is typically defined as a high permeability conduit that can serve as a high-capacity transport pathway for volatile organic compound (VOC) vapors from the source area to or into a building. More specifically, the Navy VI Evaluation Tool (Caldwell 2012) uses the definition: "Preferential pathways are natural or anthropogenic subsurface features of higher permeability or air filled porosity than the surrounding matrix. Preferential pathways may transport vapors farther or faster than what would be predicted by vapor transport models or assumptions (i.e., the Johnson and Ettinger model or attenuation factors)" (Caldwell 2012). Some have further defined the term "atypical preferential pathway" to refer to a building feature that is not commonly found in association with most structures of the same general class (i.e., single family residences, office buildings). If sufficiently deep, elevator shafts, dry wells or cisterns can act as vertical preferential pathways enhancing the transport of VOC vapors into a building from a groundwater source located below the building. Sewers or utility tunnels can also serve as preferential pathways for vertical and lateral migration of VOC vapors (Figure 1). Sewers or utility tunnels are of greatest concern when they pass directly through contaminated groundwater or vadose zone non-aqueous phase liquid (NAPL) sources since those locations could provide the highest concentration infiltration into the conduit. When sewers pass through contaminated groundwater, this groundwater may infiltrate into the sewer allowing partitioning into the gas phase to occur within the sewer line. In these cases, vapor intrusion impacts may occur in buildings laterally offset from the groundwater plume but connected to the sewer line running through the plume (Figure 1). 


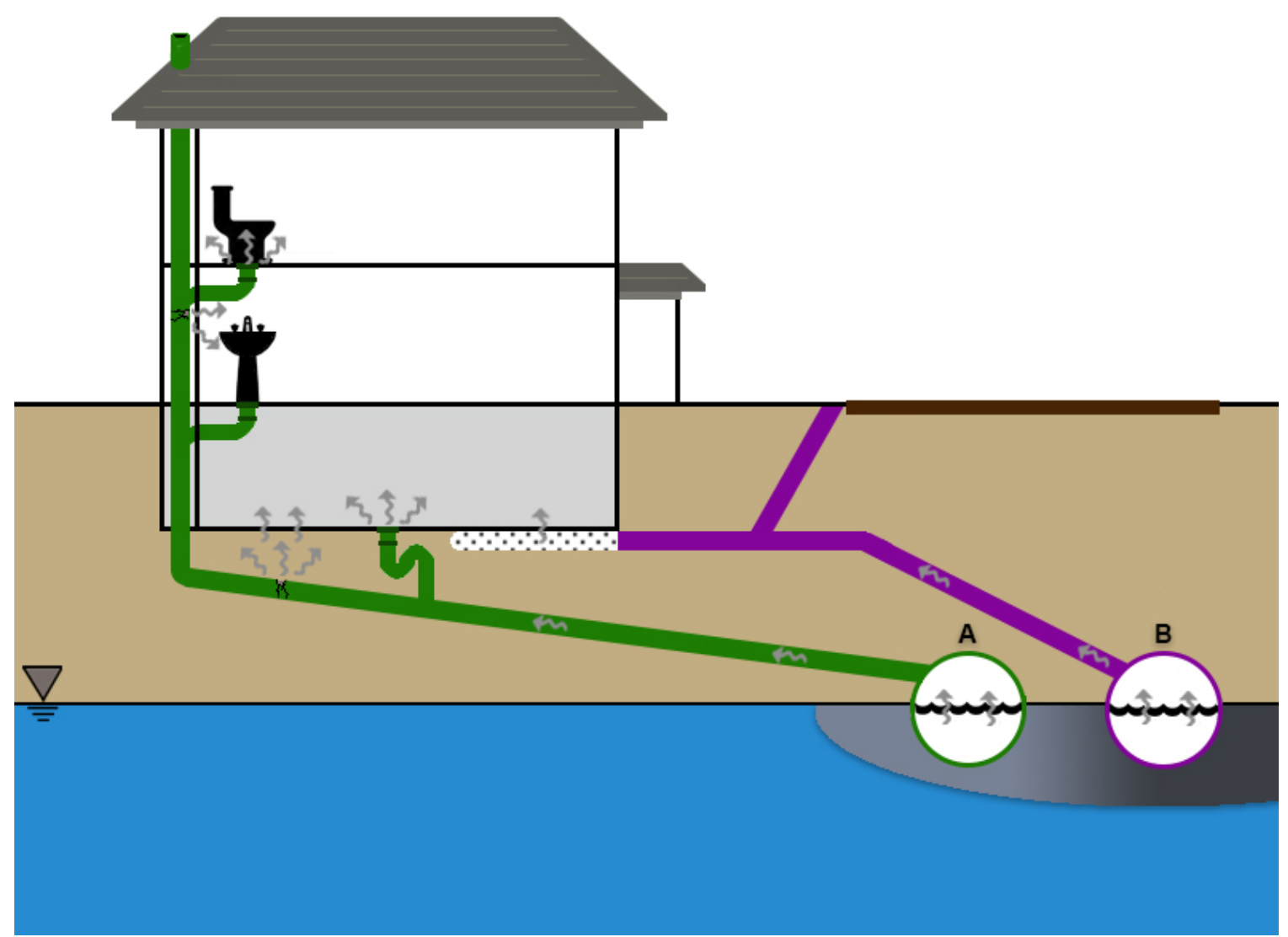

Figure 1. Conceptual illustration of sewer preferential pathways for vapor intrusion. A) Most residences (i.e., those without septic tanks), are connected to the sanitary (or combined storm and sanitary) sewer system. B) Some residences have foundation drain systems connected to land drain or storm sewer systems. Although prohibited by current building codes, some residences may have older or illegal foundation drains connected to the sanitary sewer system. Clean-outs and manholes are not shown.

Storm sewers, sanitary sewers, and utility tunnels have been identified as important preferential transport pathways for VOC vapor intrusion at a small but growing number of sites. Examples include: vinyl chloride vapor intrusion at a former dry cleaner site (Nielsen, et al. 2014), several houses near a tetrachloroethene (PCE) plume in Denmark (Riis, et al. 2010), a house at Hill Air Force Base Operable Unit 2 (McHugh, et al. 2011), a Boston area house (Pennell, et al. 2013), and a building at Moffett Field, California (McHugh et al., 2012).

The USEPA vapor intrusion research duplex is a residence in Indianapolis, Indiana that has been intensively studied in order to better understand vapor intrusion processes (USEPA, 2012; USEPA, 2015a; USEPA, 2015b; Lutes 2015). Since 2011, a USEPAfunded research team has monitored VOC concentrations and other parameters in indoor air, soil gas, and groundwater. Similar to the research house in Utah (Holton et al., 2013), the USEPA team found large spatial and temporal variations in VOC concentrations in indoor air, subslab, and soil gas. Geophysical testing in and around the research duplex confirmed the location of many known features and suggested that the concrete basement 
1

slab varied in thickness. The basement slab has an irregular contact with the underlying fill material resulting in air gaps. Helium tracer testing with injection at deep external soil gas points showed spatial variations in helium concentrations that indicate subsurface heterogeneity and possible preferential flow paths below the foundation of the research duplex. Temporal variations in PCE and chloroform within the duplex have been attributed to several factors including exterior temperatures, heating system usage, barometric pressure, indoor humidity, and possibly wind effects. Based on differences in the spatial distribution of PCE vs. chloroform as well as differences in the observed temporal changes in concentration, the USEPA study team concluded that these two compounds may originate from different primary sources (e.g., former dry cleaner site vs. water disinfection by-product; USEPA, 2012). In 2013, a sub-slab depressurization system was installed in the duplex as part of the research effort. The system was operated intermittently from 2013 to 2015, but has been off since March 20, 2015.

Some of the VOC concentration results collected from the USEPA research duplex have not been consistent with the standard conceptual model for vapor intrusion suggesting the possibility of a preferential pathway. For example, PCE and chloroform concentrations in groundwater are generally less than $1.5 \mathrm{ug} / \mathrm{L}$ while the concentrations in indoor air have, at times, exceeded $10 \mathrm{ug} / \mathrm{m}^{3}$ for PCE, much higher than the $1.2 \mathrm{ug} / \mathrm{m}^{3}$ upper-bound concentration predicted using the USEPA $95^{\text {th }}$ percentile screening attenuation factor of 0.001 (USEPA, 2015c). In addition, the PCE concentrations in sub-slab soil gas are sometimes higher than at sample points deeper within the vadose zone suggesting an absence of upward diffusion from the water table. Finally, early in the study, high concentrations of PCE and chloroform (each approximately $300 \mathrm{ug} / \mathrm{m}^{3}$ ) were measured in a floor drain on the first floor of the duplex (USEPA, 2012). Subsequently, all of the floor drains on the upper floors were plugged to prevent direct entry of sewer vapors into the duplex. A floor drain in the basement needed for the furnace was not plugged.

The purpose of this study was to measure VOC concentrations in the sewer line connected to the USEPA research duplex and to perform other testing to evaluate the role of a sewer preferential pathway at this duplex. Aside from one round of floor drain testing in 2011, VOC concentrations in the duplex sewer system were not measured prior to our field study.

\subsection{Methods}

\subsection{Overview of the testing program.}

The field sampling program was conducted from June 12 to June 16, 2016. Vapor samples were collected from sewer manholes, existing soil gas and sub-slab monitoring points, the sewer lateral line connecting the duplex to the sewer main, and locations inside the duplex. Liquid samples were collected from three sewer manholes and two existing groundwater monitoring wells. The analytical testing program included on-site analysis of vapor samples, off-site laboratory analysis for vapor and liquid samples, and a tracer study.

\subsection{Vapor sample collection.}

Vapor samples were collected from sewer manholes through existing vent holes in the manhole cover or by moving the cover enough to allow passage of the sampling tube. Liquid levels were measured using a water level meter. Vapor samples were collected at a depth of approximately $0.3 \mathrm{~m}$ above the liquid level or $0.3 \mathrm{~m}$ above the base of the manhole in cases where the liquid did not cover the base outside of the invert flow channel. Vapor samples were collected using weighted, $3 \mathrm{~mm}$ outside diameter Nylaflow tubing lowered to the sample collection depth. Prior to sample collection, more than three line 
1

volumes of air (approximately $50 \mathrm{~mL}$ ) were purged from the tubing using a 3-way valve and gas-tight syringe. Samples were collected in 1-L Tedlar bags using the 3-way valve and gas-tight syringe or in 1-L Summa canisters without flow controllers. Collection of vapor samples from the existing soil gas and sub-slab monitoring points involved similar procedures for line purging and sample collection. The sewer lateral line was sampled by drilling a hole into the PVC sewer lateral pipe in the duplex basement and installing a sampling port sealed in place with modeling clay. These sewer lateral sampling ports remained in place throughout the field program. Indoor air samples were collected directly, either by grab sampling with 1-L Summa canisters, or by using a HAPSITE Smart Plus Gas Chromatograph/Mass Spectrometer (GC/MS) (Inficon, New York). In the latter case, samples were collected into the instrument using the hand-held HAPSITE probe.

A total of 55 vapor/air samples were collected. Thirty-nine (39) of these were analyzed on-site using the HAPSITE GC/MS (after Gorder and Dettenmaier, 2011). The remaining 16 samples collected in Tedlar bags and Summa canisters were shipped to the TestAmerica laboratory in Sacramento, CA, a National Environmental Laboratory Accreditation Program (NELAP) certified commercial analytical laboratory, for analysis by USEPA Method TO-15 (USEPA, 1999). Tedlar bags were shipped for overnight delivery and were transferred by the laboratory into Summa canisters to avoid exceeding holding time limits. Due to operational difficulties with the HAPSITE GC/MS, no replicate samples were analyzed both on site and by the offsite laboratory.

\subsection{Liquid sampling and analysis.}

Water and sewer liquid samples were collected from two existing monitoring wells (MW1A and $\mathrm{MW1C}$ ) and three sewer manholes, respectively. All samples were collected using low-flow purge methods. Samples were shipped on ice to TestAmerica for analysis using USEPA Method 8260B (USEPA, 1996).

\subsection{Tracer study.}

The tracer study was conducted using the Brookhaven National Laboratory's Air Infiltration Measurement System which utilizes passive perfluorocarbon tracer (PFT) sources and passive capillary adsorption tube samplers (CATS; Dietz et al., 1986, Winberry 1990). To evaluate the interaction between the sewer and duplex, PFT sources, each emitting a different perfluorocarbon compound, were deployed in 6 different areas (Table 1). To deploy the sources in the manholes, the sources were attached to a weighted line and suspended approximately $0.5 \mathrm{~m}$ above the top of the sewer line. Sources were deployed on the first day of the study and remained in place throughout the testing period. After 4 hours, the CATS were deployed (Table 1, Figure S.1). The CATS were retrieved 93 hours (approximately four days) after deployment and shipped to the Brookhaven National Laboratory (certified through the New York State Department of Health Environmental Laboratory Approval Program) for analysis by GC-Electron Capture Detector (ECD) (Watson et al., 2007). Similar methodologies had previously been used to determine air exchange rates for the structure (US EPA 2015a) but the previously used sources had been removed long before the current testing.

Table 1. Tracer Source and Sampler Locations

\begin{tabular}{|c|c|c|}
\hline Deployment Location & PFT Source Type & CATS ID \\
\hline 422 Main Floor & PDCB & 10708,00126 \\
\hline 422 Basement & iPPCH & 10251,05395 \\
\hline 422 SN Lateral & PTCH & 00300,05778 \\
\hline
\end{tabular}




\begin{tabular}{|c|c|c|}
\cline { 3 - 3 } 420 Main Floor & None & 02783,10249 \\
\hline 420 Basement & ocPDCH & 07471,04441 \\
\hline 420 SN Lateral & None & 10379,04295 \\
\hline SN Main Upstream & PMCH & 01403,07658 \\
\hline SN Main Downstream & PMCP & 07694,10689 \\
\hline
\end{tabular}

Note: The PFT sources were deployed on the first day of the study and the CATS were deployed four hours later. The PFT sources and the CATS were retrieved 93 hours after CATS deployment. Locations are shown in Figure S.1. PFT source compound abbreviations are defined in the supporting materials.

\subsection{Results}

The field sampling program at the duplex consisted primarily of i) VOC concentration measurements of sewer manhole vapor, soil gas, indoor air, groundwater, and sewer liquid, and ii) a tracer study using PFT compounds released at the sewer manholes and inside the duplex. Sampling was conducted from June 12 to June 16, 2016. The field sampling program was complicated by two thunderstorm events that occurred on the afternoons of June 14 and June 15, which resulted in 2.4 inches and 3.0 inches of precipitation, respectively. Because the sewer line connected to the duplex is a combined storm and sanitary sewer, these rain events resulted in very high water flows through the sewer during both afternoons.

\subsection{PCE and Chloroform in the Immediate Vicinity of the Duplex}

PCE and chloroform were previously identified as the primary constituents of concern for vapor intrusion at this site (USEPA 2012). PCE and chloroform concentration results for all samples are provided in Table S.1 and S.2. Figure 2 summarizes PCE and chloroform concentrations measured in vapor and liquid samples collected from the immediate vicinity of the duplex. PCE and chloroform concentrations measured in the sub-slab and soil gas sample points were similar to those measured at other times during 2016 as part of the long-term study of the duplex, however, these concentrations were lower than those measured at the same sample points in the earlier years of the study (see Figures S.2 and S.3). As shown in Figure 2, both PCE and chloroform concentrations in vapor samples collected from the sewer line were similar to those measured in soil gas samples collected from below the duplex. Before the two storm events, concentrations in the sewer were slightly higher than in soil gas and, after the storm events, concentrations in the soil gas were slightly higher than in the sewer. PCE and chloroform concentrations in the sewer lateral line in the duplex basement were lower than in the sewer manhole but higher than in indoor air. PCE and chloroform concentrations in groundwater and sewer liquids were measured only after the storm events. PCE concentrations were non-detect or less than $1 \mathrm{ug} / \mathrm{L}$ in all sewer liquid samples. Chloroform concentrations were slightly higher in the sewer liquids $(4.4 \mathrm{ug} / \mathrm{L})$ than in the groundwater $(1.7$ and $2.1 \mathrm{ug} / \mathrm{L})$. 
A)

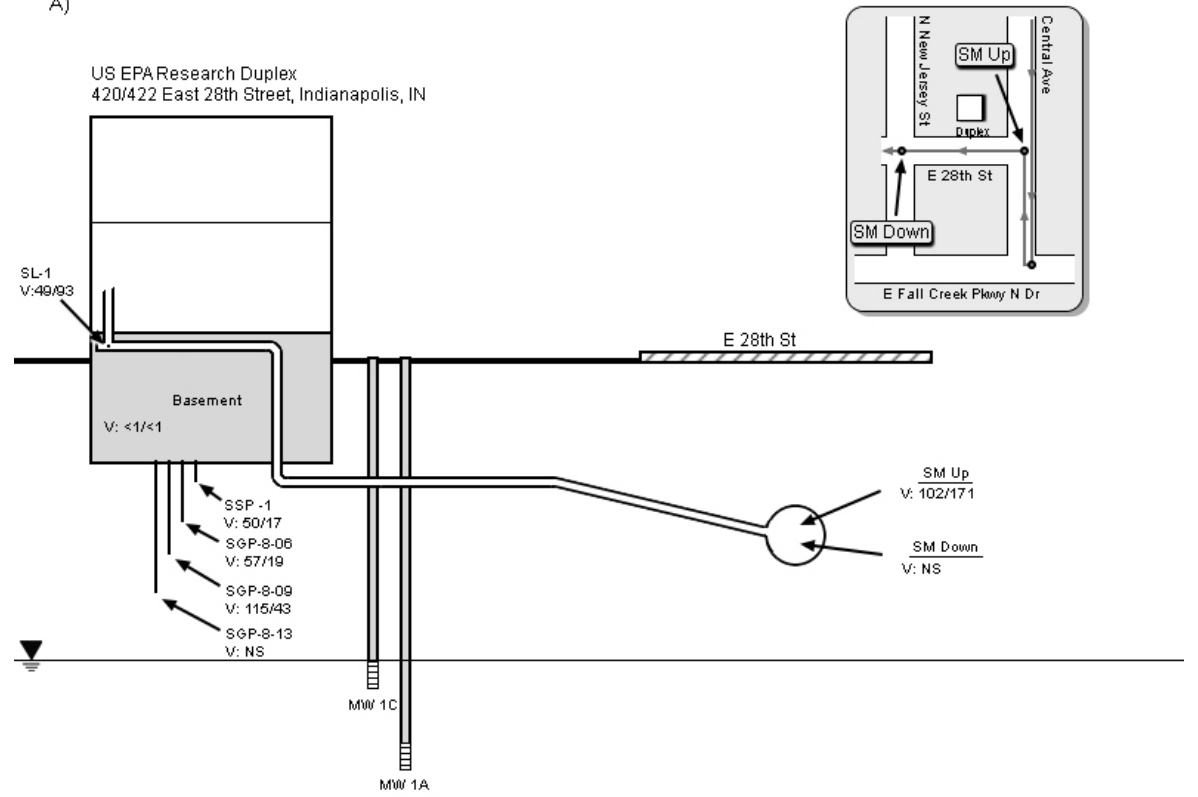

2

B)

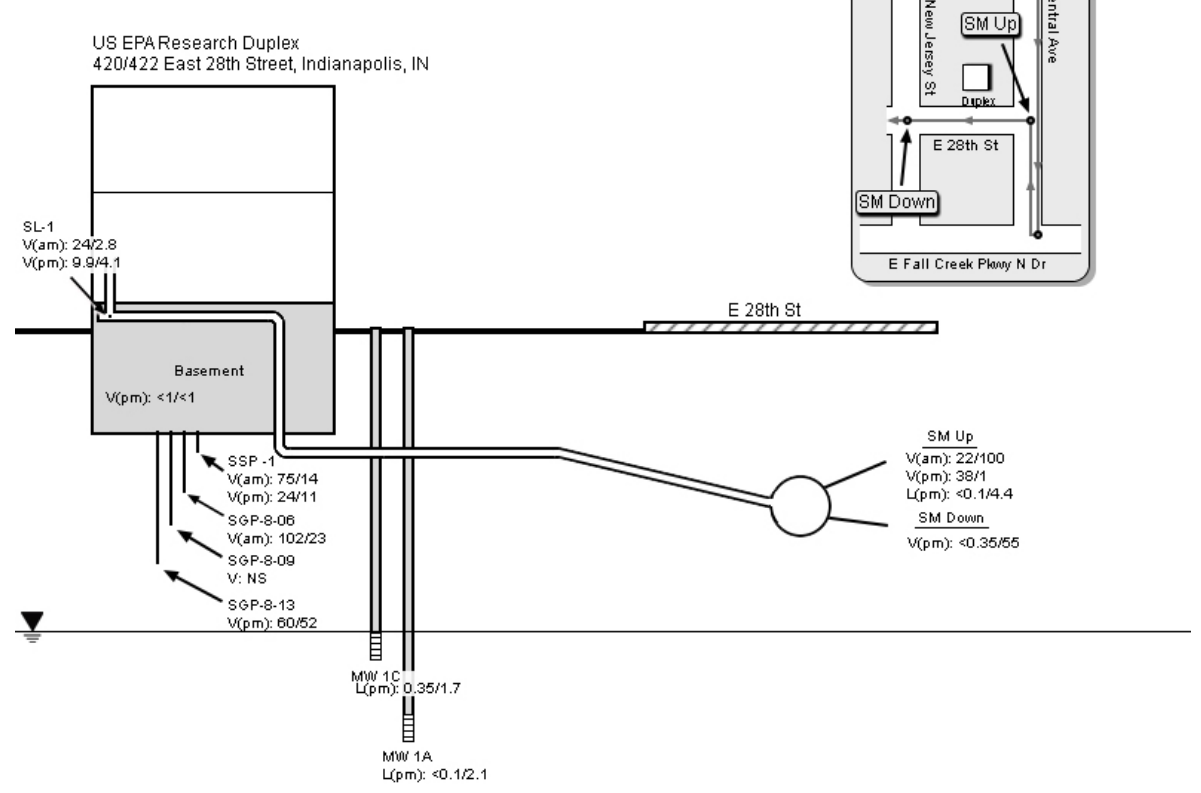

4

Figure 2. VOC Concentration (PCE/Chloroform) results for samples collected in the immediate vicinity of the USEPA Research Duplex. V - vapor sample $\left(\mathrm{ug} / \mathrm{m}^{3}\right), \mathrm{L}-$ Liquid sample (ug/L). Panel A: Samples collected 6/12-13/2016 before two storm events on 6/14 and 6/15. Panel B: Samples collected on the morning (am) or afternoon (pm) of 6/16/2016 after the two storm events. NS $=$ Not sampled. SL-1 is a sample port installed in the sewer lateral line that runs through the 420 side of the duplex basement. "SM Up" and "SMDown" are the sewer manholes immediately upstream and downstream of the duplex. 
Page 8 of 16

\subsection{PCE in Sewer Manholes Away from the Duplex} In addition to testing in and around the duplex, the field program included collection and analysis of vapor and liquid samples from sewer manholes further upstream of the duplex along Central Avenue and other adjacent streets (Figure 3). At least two former dry cleaner sites with documented PCE plumes in groundwater are located on Central Avenue north (upstream) of the duplex. PCE was detected in upstream manholes at concentrations ranging from 0.6 to $353 \mathrm{ug} / \mathrm{m}^{3}$. The highest PCE concentration $\left(353 \mathrm{ug} / \mathrm{m}^{3}\right)$ was measured in a manhole adjacent to one of the dry cleaner sites. In addition, PCE concentrations above $100 \mathrm{ug} / \mathrm{m}^{3}$ were detected in several manholes upstream of the two known dry cleaner sites. At the duplex and adjacent to the two former dry cleaner sites, the manhole depths were shallower than the documented depth of groundwater in those areas, suggesting that PCE detected at these locations was not attributable to the local infiltration of groundwater into the sewer (Table S.3). However, information on groundwater depth was not available for manholes further upstream. As a result, it is not clear whether the PCE detected in manholes is primarily attributable to local infiltration of soil gas or upstream sources such as infiltration of contaminated groundwater or discharge of wastewater containing PCE. Similar to the manholes adjacent to the duplex, PCE concentrations in the upstream manholes were higher before the two storm events than after these events. Elevated chloroform concentrations were widely distributed across the manholes tested, consistent with discharges of chlorinated water and bleach into the sewer system as likely sources. 


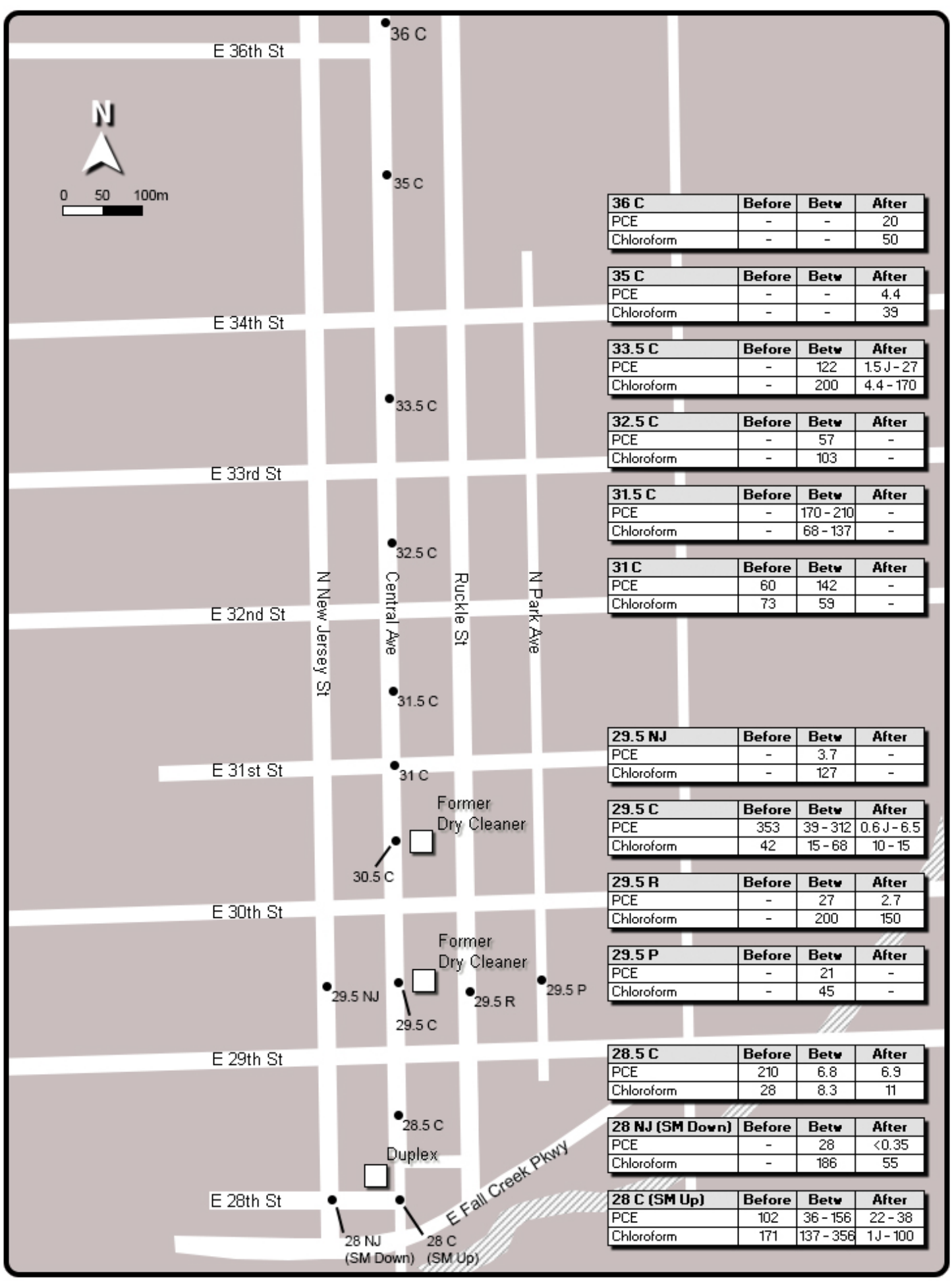

Figure 3. VOC Concentration (PCE and Chloroform, ug $/ \mathrm{m}^{3}$ ) results for vapor samples collected in the vicinity of the duplex. Before $=$ Samples collected on June 13 or June 14 prior to the first storm event. Btwn = samples collected on the morning of June 15 between the first and second storm events. After = samples collected on June 16 after the second storm event. 
1

\subsection{Results of Tracer Study}

Six PFT compounds were used to evaluate air movement within the duplex and between the duplex and the sewer line. Source release locations and CATS locations are shown on Figure S.1. Both the sources and the CATS deployed in the two manholes were covered by storm water flow during the two storm events. Visual inspection of the CATS following the first storm event showed an absence of water inside the CATS tubes. However, when the CATS were collected on June 17, one CATS (ID 10689) from the downstream sanitary sewer manhole sample location had a thin film of water covering the opening of the tube that likely affected the tracer uptake for that tube. The results for this CATS are reported in the supplemental materials, but are not considered for the interpretation of the tracer study results.

At two CATS locations (SN Main Upstream and 422 SN Lateral), one of the two samplers was collected early, on June 15 at 11:30 am, in order to evaluate the effect of water inundation on the tracer release from the sources and the uptake by the CATS. The difference in average tracer concentrations for the samplers with different exposure durations was small (Relative Percent Differences of $10 \%$ to $52 \%$ ) with no clear difference between sources in the sewer mains that were inundated by the storm events and sources in the house that were not. This suggests that the inundation events had only a minor effect on the rate of tracer release from the sources in the sewer mains. Additional information on the results from the tracer testing is provided in the Supplemental Materials.

The tracer study demonstrated air exchange between the sewer line and the duplex based on detection of tracer released in both upstream and downstream sewer manholes inside the duplex. Tracer attenuation factors were calculated for each of the two sewer manholes as the tracer concentration in the duplex divided by the tracer concentration in the sewer manhole. At each location, the tracer concentration was measured using the CATS deployed over the four-day test period (i.e., the tracer concentration was the average concentration over the four-day test period). Sewer to indoor air attenuation factors ranged from $<0.001$ to 0.006 for the upstream manhole and 0.010 to 0.021 for the downstream manhole (Table 2), indicating approximately 500x dilution of vapors from the upstream manhole to indoor air and $50 x$ dilution of vapors from the downstream manhole. The sewer to indoor air attenuation factors were similar in the basement and main floor. The two storm events that occurred during the four-day tracer release period resulted in two periods of high storm water flows that completely filled the sewer line and backed water into the manholes. Although the tracer study documents gas exchange between the sewer line and the duplex, the attenuation factors measured may not be representative of more typical weather conditions when flows through the sewer are lower.

The tracer compounds released into the sewer manholes were detected at the sewer lateral sample points at concentrations higher than those detected inside the duplex demonstrating migration through the sewer lateral. Tracer concentrations detected in the sewer lateral sample points indicated similar magnitude of transport into the sewer lateral from the upstream manhole and the downstream manhole (see Supplemental Material, Tracer Study Report). It is not clear why higher amounts of tracer from the downstream manhole were detected inside the duplex. In addition, the tracer compound released directly into the sewer lateral inside the basement was not detected within the air of the duplex at any of the four sampling locations. This indicates limited leakage from the sewer lateral lines running through the basement of the duplex. Instead, the results suggest that 
1

the sewer lateral leaks below the duplex foundation and that sewer vapors then enter the duplex through the foundation.

\section{Table 2. Sewer Main to Indoor Air Attenuation Factors Measured Using Perfluorocarbon Tracer Compounds}

\begin{tabular}{|l|c|c|}
\hline Source Location & Duplex Location & Attenuation Factor \\
\hline \multirow{3}{*}{$\begin{array}{l}\text { Sewer Manhole } \\
\text { Upstream }\end{array}$} & 422 Basement & 0.004 \\
\cline { 2 - 3 } & 422 Main Floor & 0.006 \\
\cline { 2 - 3 } & 420 Basement & $<0.001$ \\
\cline { 2 - 3 } & 420 Main Floor & $<0.001$ \\
\hline \multirow{3}{*}{$\begin{array}{l}\text { Sewer Manhole } \\
\text { Downstream }\end{array}$} & 422 Basement & 0.015 \\
\cline { 2 - 3 } & 422 Main Floor & 0.018 \\
\cline { 2 - 3 } & 420 Basement & 0.010 \\
\cline { 2 - 3 } & 420 Main Floor & 0.021 \\
\hline
\end{tabular}

\subsection{Discussion}

The tracer, sewer vapor, soil gas, and indoor air testing conducted during the field investigation confirmed that the sewer line can serve as a local preferential pathway for migration of volatile chemicals from the sewer main into the duplex. This is evident because i) PCE and chloroform were detected at multiple locations within the sewer line serving the duplex and ii) tracers released in the upstream and downstream manholes were detected in the duplex sewer laterals and in indoor air. However, the migration pathway is complex. Tracer released in the sewer lateral running through the basement of the duplex was detected within the lateral, but not in any other location, suggesting limited leakage from the lateral itself inside the duplex. Taken together, the tracer data suggest that the sewer lateral line may leak at some point below the duplex foundation followed by migration into the duplex by other mechanisms. The sewer manhole tracer compounds were detected on the main floor of the duplex at concentrations that were $1.2 \mathrm{x}$ to $1.8 \mathrm{x}$ higher than measured in the basement suggesting some transport of tracer compounds to the main floor that by-passed the basement.

Tracer compounds released inside the duplex showed modest mixing between the basement and the main floor. Tracer compounds released in the basement were detected on the main floor at concentrations of 15 to $30 \%$ of those measured in the basement, while the tracer compound release on the main floor was measured in the basement at only $2.5 \%$ of the main floor concentration (see Supplemental Material, Tracer Study Report). During the multi-year study of the duplex, PCE concentrations on the main floor were typically lower than in the basement, averaging about $50 \%$ of the basement concentration. Chloroform concentrations on the main floor averaged about $80 \%$ of the concentration in the basement, but were higher on the main floor than in the basement during approximately $25 \%$ of the sample events. These data suggest that some PCE and chloroform may reach the main floor though pathways that by-pass the basement (e.g., through wall gaps). However, the differences in distribution within the duplex between the sewer manhole tracer compounds, PCE, and chloroform suggest that there may be some differences in how these compounds enter the duplex and migrate within the duplex.

In addition to the June 2016 field program, prior testing at the duplex suggested a role for the sewer line in transport of PCE and chloroform to the duplex. The prior test results 
suggest that, at least during some time periods, the sewer line was the primary transport pathway from the VOC source to the building envelope:

- PCE and chloroform concentrations in sub-slab samples were commonly greater than or equal to those measured in matched deeper soil gas samples (Figure S.2, S.3, S.4, and S.5). This suggests an absence of upwards diffusion of VOCs from a local groundwater source and indicates, instead, an alternate mechanism for VOC vapor transport to the sub-slab soils. This pattern of VOC distribution below the residence was one line of evidence pointing to a preferential transport pathway at the ASU research house in Utah (Guo et al., 2015).

- When floor drains were tested in May 2011, PCE and chloroform concentrations in the first floor laundry area floor drain were each approximately $300 \mathrm{ug} / \mathrm{m}^{3}$. These concentrations were much higher than measured in indoor air and also higher than measured in sub-slab soil gas sample points during that immediate time frame. Although floor drains were plugged after this testing, this plugging would not affect transport of vapors through the sewer to a leak point below the foundation.

In late 2012 and early 2013, testing of a newly-installed sub-slab depressurization system provided additional evidence for a preferential pathway for VOC transport to the duplex:

- Operation of the mitigation system consistently reduced indoor radon concentrations by more than $90 \%$. However, episodic PCE vapor intrusion events occurred during operation of the mitigation system that were similar to those observed when the mitigation system was not operating (Figure S.6 and S.7).

- The mitigation system resulted in a large reduction in radon concentration in the soil gas below the duplex but had only a small effect on PCE and chloroform concentrations below the duplex (Figures S.8, S.9, and S.10). This suggests that the mitigation system was drawing PCE and chloroform vapors from a large reservoir such as the sewer line. The alternate interpretation that the mitigation system was primarily drawing air from greater depth is not consistent with the relatively uniform concentration of radon with depth premitigation (Figure S.8).

- The mass flux of PCE and chloroform captured by the mitigation system was 25 to 50 times higher than the mass flux of these VOCs through the duplex in the absence of mitigation (USEPA, 2015b). This, again, suggests that the mitigation system was capturing PCE and chloroform from a large reservoir such as the sewer system.

Combined, these observations indicate a clear role for the sewer line in transport of VOCs to the duplex. The 2016 field program results, however, were less definitive concerning the primary source of PCE and chloroform: a local groundwater plume vs. infiltration of contaminated groundwater into the sewer line at a location upstream of the duplex. Throughout the long-term study of the duplex, PCE concentrations in groundwater have generally been less than $1.5 \mathrm{ug} / \mathrm{L}$ while chloroform concentrations have ranged from $<1$ $\mathrm{ug} / \mathrm{L}$ to $3 \mathrm{ug} / \mathrm{L}$. The detection of PCE in sewer liquids at a concentration well above $1 \mathrm{ug} / \mathrm{L}$ would have provided strong evidence that PCE was migrating through the sewer line. The sewer liquids collected during the field program from the upstream manhole contained non-detect PCE concentrations ( $<0.1 \mathrm{ug} / \mathrm{L})$ and $4.4 \mathrm{ug} / \mathrm{L}$ of chloroform. However, these samples were collected only 24 hours after the second of the two storm events. PCE vapor concentrations were lower during this time period compared to before the storm events suggesting that the post-storm liquid concentrations may not be representative of sewer liquids during drier periods. PCE was detected in sewer vapor samples collected 
from manholes along Central Avenue upstream of the duplex at concentrations up to 353 $\mathrm{ug} / \mathrm{m}^{3}$ (Figure 3). Taken as a whole, the sewer test results suggest that PCE could be transported through the sewer line from upstream sources, but they do not demonstrate that this is occurring or that it is the primary source of PCE for vapor intrusion at the duplex. A longer monitoring period would be required to resolve this.

While PCE in the sewer liquids would likely originate from infiltrating groundwater associated with an upstream plume, chloroform would likely be associated with domestic wastewater. Chloroform is a disinfection by-product commonly found in public water supplies at concentrations of 2 to $44 \mathrm{ug} / \mathrm{L}$ (ATSDR, 1997). In addition, chloroform is a reaction product of chlorine bleach cleaner and organic material (Odabasi, 2008). As a result, after a storm event, chloroform is likely to return to the sewer line more quickly than PCE. During the field program, chloroform concentrations in the sewer liquids (3.6 to 4.4 $\mathrm{ug} / \mathrm{L}$ ) were approximately twice the concentration measured in groundwater at the duplex suggesting that the sewer is the more important source of chloroform for vapor intrusion. In fact, it is possible that the chloroform detected in groundwater is attributable to sewer exfiltration (Amick, 2000).

Regardless of whether the sewer lines are transporting liquids from a remote source, the results of the field program and prior testing of the duplex confirm that the sewer line can act as a local reservoir and transport pathway for PCE and chloroform vapors from the subsurface source into the building envelope. In addition, elevated concentrations of PCE and chloroform were detected in sewer vapor samples at most of the manholes tested in the area. These results, as well as recent findings from other studies (Guo et al., 2015; Nielsen et al., 2014; Riis et al., 2010; McHugh et al., 2011; Pennell et al., 2013; McHugh et al., 2012), suggest that the role of sewer lines in vapor intrusion should be routinely evaluated as part of vapor intrusion investigations.

\section{Acknowledgements}

This research was funded in part by the U.S. Department of Defense, through Environmental Security Technology Certification Program (ESTCP) Project ER-201505 and in part by the USEPA through its Office of Research and Development under contract EP-C-11-036 to RTI International. The USEPA collaborated in the research described here and it has been subjected to Agency review and approved for publication. Mention of trade names or commercial products does not constitute endorsement or recommendation for use.

\section{Supplementary Materials}

Supplementary materials to this article are available.

\section{References}

Agency for Toxic Substances and Disease Registry, 1997. Toxicological Profile for Chloroform. https://www.atsdr.cdc.gov/toxprofiles/tp6.pdf (Accessed 25 October 2016).

Amick, R.S., 2000. Exfiltration in Sewer Systems, EPA/600/R-01/034, December 2000. 
Page 14 of 16

Caldwell, D., 2012. Navy Vapor Intrusion Evaluation Tool. EMDQ 2012 Workshop.

Dietz, R.N., Goodrich, R.W., Cote E.A., and Wieser, R.F., 1986. Detailed description and performance of a passive perfluorocarbon tracer system for building ventilation and air exchange measurements, Measured Air Leakage of Buildings, ASTM STP 904, p. 20364, American Society for Testing and Materials, Philadelphia.

Gorder, K.A., and Dettenmaier, E.M., 2011. Portable GC/MS Methods to Evaluate Sources of cVOC Contamination in Indoor Air. Ground Water Monit. R. 31 (4), 113-119. DOI: $10.1111 / j 1745-6592.2011 .01357 . x$.

Guo, Y., Holton, C., Luo, H., Dahlen, P., Gorder, K., Dettenmaier, E., and Johnson, P., 2015. Identification of Alternative Vapor Intrusion Pathways Using Controlled Pressure Testing, Soil Gas Monitoring, and Screening Model Calculations. Environ. Sci. Technol. 49(22), 13472-13482. DOI: 10.1021/acs.est.5b03564.

Holton, C., Luo, H., Dahlen, P., Gorder, K., Dettenmaier, E., and Johnson, P., 2013. Temporal Variability of Indoor Air Concentrations under Natural Conditions in a House Overlying a Dilute Chlorinated Solvent Groundwater Plume. Environ. Sci. Technol. 47(23), 13347-13354. DOI: 0.1021/es4024767.

Lutes, C.C., Truesdale, R.S., Cosky, B.W., Zimmerman, J.H., and Schumacher, B.A., 2015. Comparing Vapor Intrusion Mitigation System Performance for VOCs and Radon, Remediation Journal 25 (4), 7-26.

McHugh, T., Beckley, L., Bailey, D., Gorder, K., Dettenmaier, E., Rivera-Duarte, I., Brock, S., and MacGregor, I., 2012. Evaluation of Vapor Intrusion using Controlled Building Pressure, Environ. Sci. Technol. 46, 4792-4799.

McHugh, T., Kuder, T., Fiorenza, S., Gorder, K., Dettenmaier, E., and Philp, P., 2011. Application of CSIA to Distinguish Between Vapor Intrusion and Indoor Sources of VOCs, Environ. Sci. Technol. 45(14), 5952-5958.

McHugh, T., Nickels, T., and Brock, S., 2007. Evaluation of Spatial and Temporal Variability in VOC Concentrations at Vapor Intrusion Investigation Sites. Proceeding of Air \& Waste Management Association's Vapor Intrusion: Learning from the Challenges, September 26-28, 2007, Providence, RI, 129-142.

Nielsen, K. B., Hivdberg, B., and Hyldegaard, W., 2014. Vinyl Chloride in the Indoor Air Solved by Depressurization of the Sewer. Battelle Ninth International Conference on Remediation of Chlorinated and Recalcitrant Compounds Monterey, CA.

Odabasi, M., 2008, Halogenated Volatile Organic Compounds from the Use of ChlorineBleach-Containing Household Products, Environ. Sci. Technol. 42 (5), 1445-1451.

Pennell, K.G., Scammell. K.M., McClean, M.D., Ames, J., Weldon, B., Friguglietti, L., Suuberg, E., Shen, R., Indeglia, P.A., and Heiger-Bernays, W.J., 2013. Sewer Gas: An Indoor Air Source of PCE to Consider During Vapor Intrusion Investigations, Ground Water Monit. R. 33(3), 119-126. 
1

Riis, C., Hansen, M.H., Nielsen, H.H., Christensen, A.G., and Terkelsen, M., 2010. Vapor Intrusion through Sewer Systems: Migration Pathways of Chlorinated Solvents from Groundwater to Indoor Air. Remediation of Chlorinated and Recalcitrant Compounds, May 2010, Monterey, CA.

Tillman, F.D., and Weaver, J.W. , 2005. Review of Recent Research on Vapor Intrusion. EPA/600/R-05/106. September 2005.

USEPA, 1996. Test Methods for Evaluating Solid Waste: Physical/Chemical Methods Compendium, Method 8260B: Volatile Organic Compounds by Gas Chromatography/Mass Spectrometry (GC/MS), part of Test Methods for Evaluating Solid Waste, Physical/Chemical Methods. At https://www.epa.gov/sites/production/files/201512/documents/8260b.pdf.

USEPA, 1999. Compendium of Methods for the Determination of Toxic Organic Compounds in Ambient Air Second Edition Compendium Method TO-15 Determination Of Volatile Organic Compounds (VOCs) In Air Collected In Specially-Prepared Canisters And Analyzed By Gas Chromatography Mass Spectrometry (GC/MS) EPA/625/R-96/010b. At http://www.epa.gov/ttnamti1/files/ambient/airtox/to-15r.pdf.

USEPA, 2012. Fluctuation of Indoor Radon and VOC Concentrations Due to Seasonal Variations, EPA/600/R-12/673, September 2012.

USEPA, 2015a. Assessment of Mitigation Systems on VI: Temporal Trends, Attenuation Factors, and Contaminant Migration Routes under Mitigated and Non-mitigated Conditions. EPA/600/R-13/241. June 2015.

USEPA, 2015b. Simple, Efficient, and Rapid Methods to Determine the Potential for VI into the Home: Temporal Trends, VI Forecasting, Sampling Strategies, and Contaminant Migration Routes. EPA/600/R-15/080. October 2015.

USEPA, 2015c. OSWER Technical Guide for Assessing and Mitigating the Vapor Intrusion Pathway from Subsurface Vapor Sources to Indoor Air. U.S. Environmental Protection Agency, Office of Solid Waste and Emergency Response. June 2015. https://www.epa.gov/vaporintrusion (accessed August 2016).

Watson, T.B., Wilke, R., Dietz, R.N., Heiser, J., and Kalb, P., 2007. The Atmospheric Background of Perfluorocarbon Compounds Used as Tracers, Environ. Sci. Technol. 41(20), 6909-6913. Doi: 10.1021/es070940k

Winberry, W.T., 1990. Compendium of Methods for the Determination of Air Pollutants in Indoor Air, Chapter IP-4: Determination of Air Exchange Rate in Indoor Air; Method IP4a Perfluorocarbon Tracer (PFT) EPA/600/4-90/010. April 1990. 


$$
\left[\begin{array}{l}
5 \\
\hline
\end{array}\right.
$$


A)

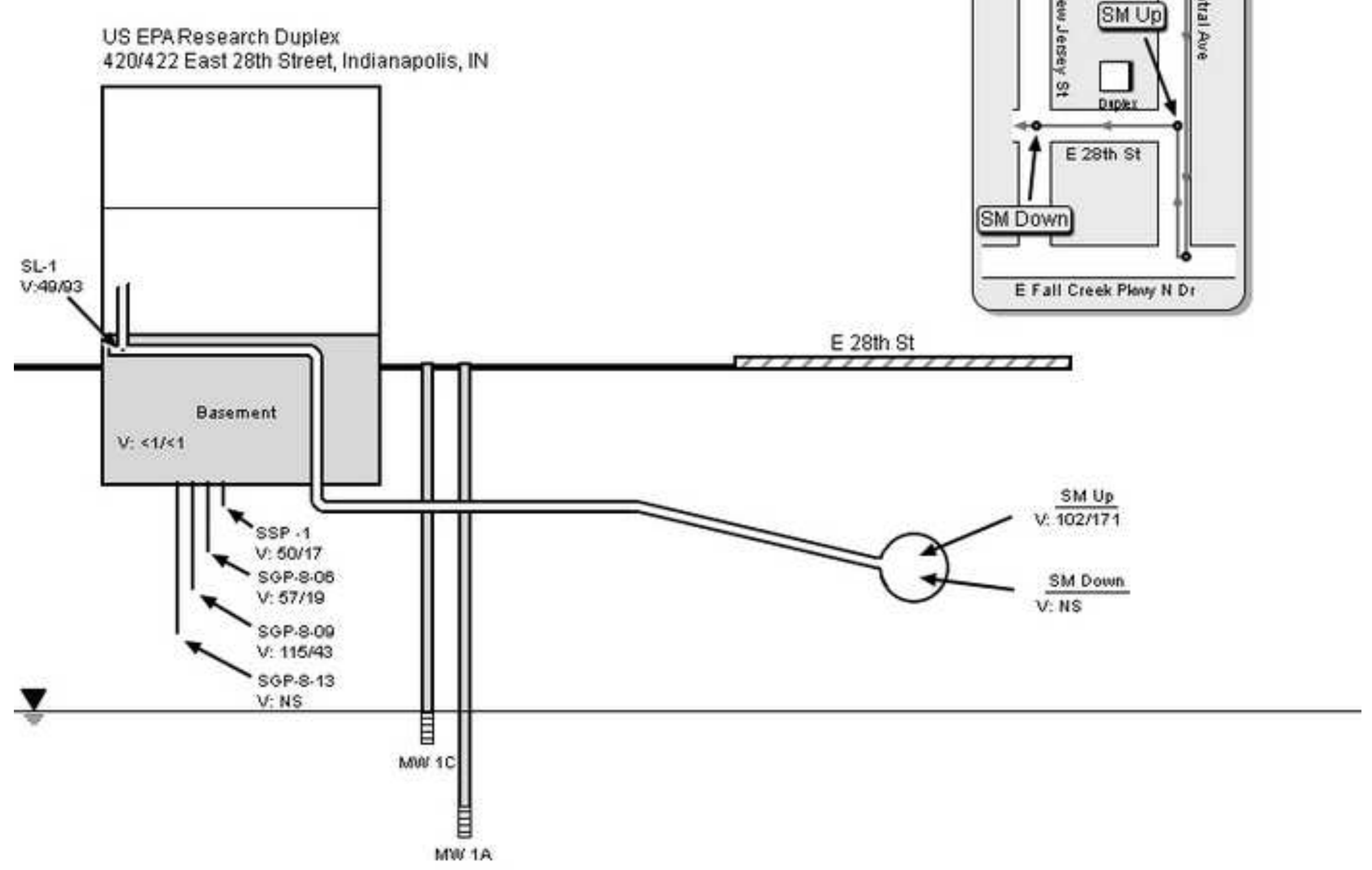


B)

US EPAResearch Duplex

$420 / 422$ East 28 th Street, Indianapolis, IN

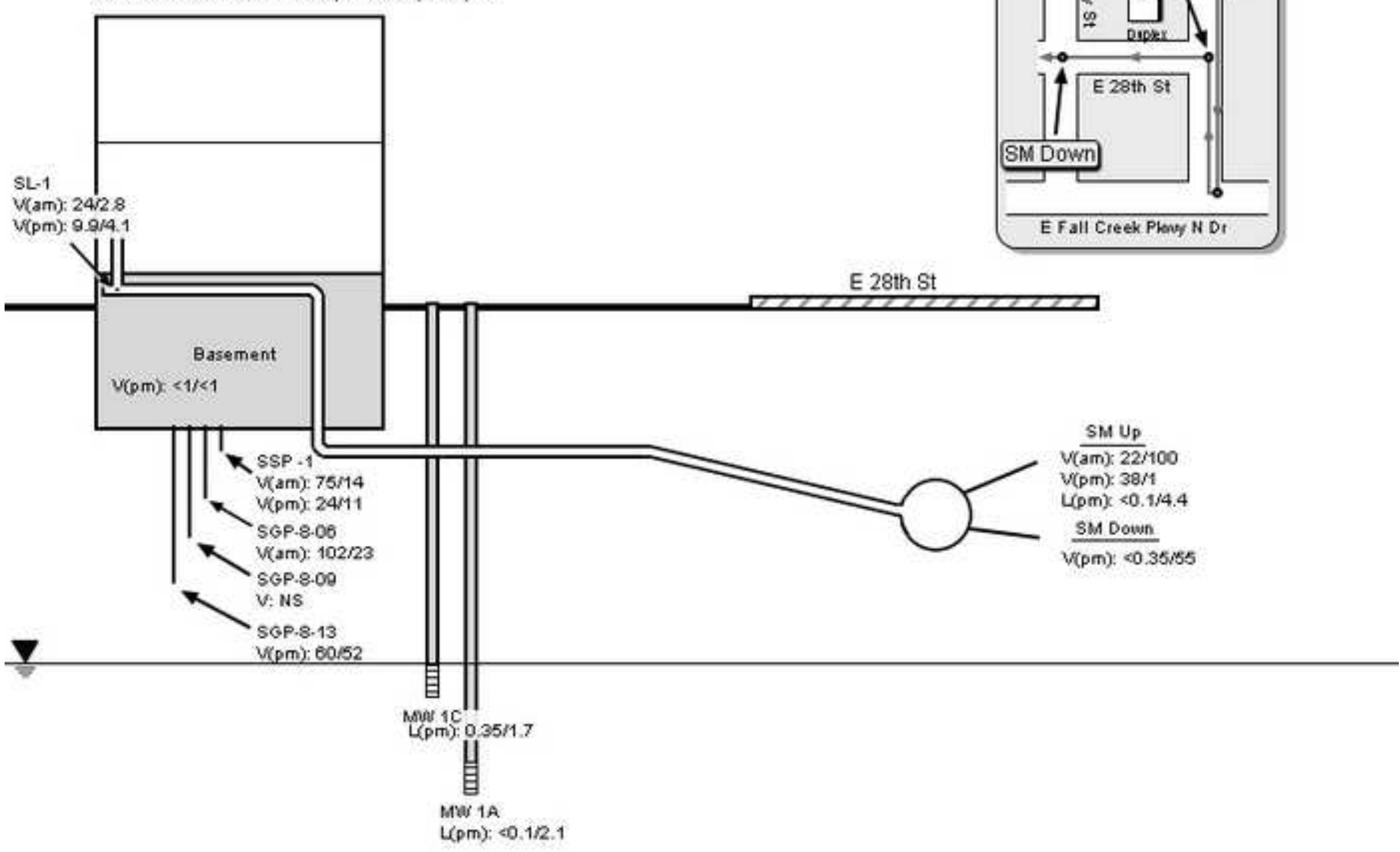




\section{E 36th St}

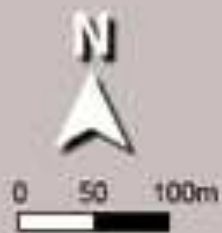

\section{E 34th St}

E 33rd St

E 32nd St

\section{E 31 st St}

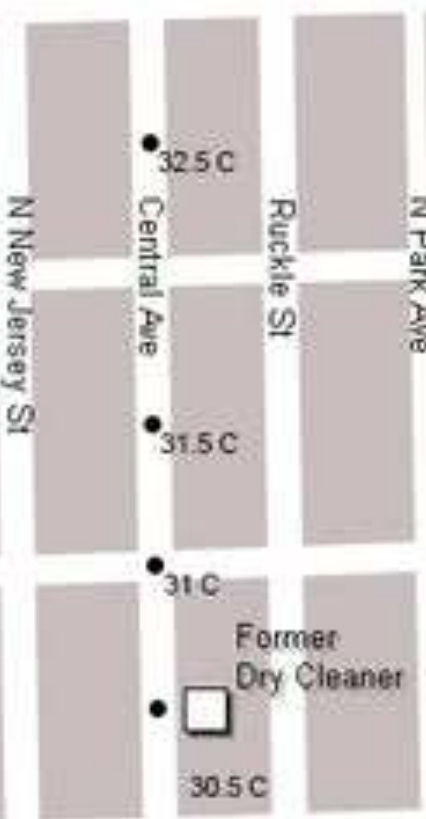

E 30th St
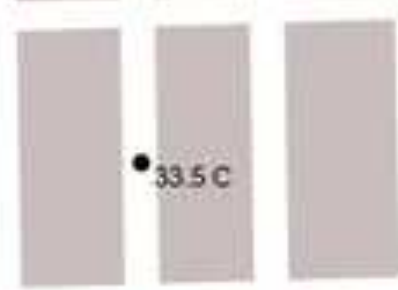

\begin{tabular}{|l|c|c|c|}
\hline $36 \mathrm{C}$ & Before & Betv & After \\
\hline PCE & - & - & 20 \\
\hline Chlocolom & - & - & 50 \\
\hline
\end{tabular}

\begin{tabular}{|l|c|c|c|}
\hline $35 \mathrm{C}$ & Before & Betv & After \\
\hline PCE & - & - & 44 \\
\hline Chileselom & - & - & 39 \\
\hline
\end{tabular}

\begin{tabular}{|l|c|c|c|}
\hline $33.5 \mathrm{C}$ & Belore & Betw & Alter \\
\hline FCE. & - & 122 & $15 \mathrm{~J}-27$ \\
\hline Chilowerem & - & 200 & $4.4-170$ \\
\hline
\end{tabular}

\begin{tabular}{|l|c|c|c|}
\hline $32,5 \mathrm{C}$ & Belore & Betw & After \\
\hline PCE & - & 57 & - \\
\hline Chlovolom & - & 103 & - \\
\hline
\end{tabular}

\begin{tabular}{|l|c|c|c|}
\hline $31.5 C$ & Betore & Betw & After \\
\hline PCE & - & $170-217$ & - \\
\hline Chlocolom & - & $68-137$ & - \\
\hline
\end{tabular}

\begin{tabular}{|l|c|c|c|}
\hline $31 \mathrm{C}$ & Before & Betv & After \\
\hline PCE & 60 & 142 & - \\
\hline Chlonotom & 73 & 59 & - \\
\hline
\end{tabular}

\begin{tabular}{|l|c|c|c|}
\hline 29.5NJ & Before & Betv & Altet \\
\hline PCE & - & 3.7 & - \\
\hline Chilootom & - & 127 & - \\
\hline
\end{tabular}

\begin{tabular}{|l|c|c|c|}
\hline $29.5 \mathrm{C}$ & Before & Betw & After \\
\hline PCE & 353 & $39-312$ & $0.6 \mathrm{~J}-6.5$ \\
\hline Chlonotom & 42 & $15-68$ & $10-15$ \\
\hline
\end{tabular}

\begin{tabular}{|l|c|c|c|}
\hline 29.5A & Before & Betv & After \\
\hline PCE & - & 27 & 2.7 \\
\hline Chlocotom & - & 200 & 150 \\
\hline
\end{tabular}

Former

Dey Cleaner
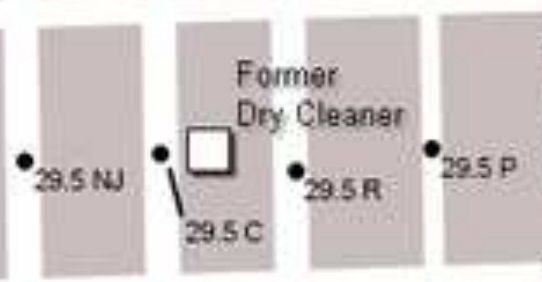

\begin{tabular}{|l|c|c|c|}
\hline $29.5 \mathrm{P}$ & Before & Betv & Altet \\
\hline PCE & - & 21 & $*$ \\
\hline Chlocotorm & - & 45 & $*$ \\
\hline
\end{tabular}

E 29th St

\begin{tabular}{|l|c|c|c|}
\hline $28.5 \mathrm{C}$ & Before & Betv & After \\
\hline PCE & 20 & 6.8 & 6.9 \\
\hline Ohbeoform & 28 & 8.3 & 11 \\
\hline
\end{tabular}

\begin{tabular}{|l|c|c|c|}
\hline 28 NJ [SM Down] & Before & Betw & After \\
\hline PCE & - & 28 & 20.35 \\
\hline Chlocelom & - & 196 & 55 \\
\hline
\end{tabular}

E 28th St

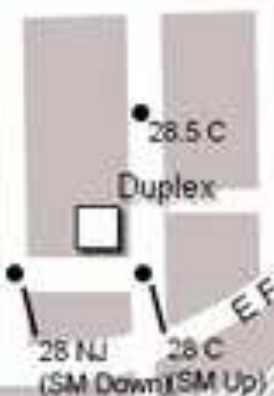

\begin{tabular}{|l|c|c|c|}
\hline $20 \mathrm{C}$ (SMUp) & Before & Betw & Alter \\
\hline PCE & 102 & $35-156$ & $22-39$ \\
\hline Chlowelom & 177 & $137-359$ & $1 J-100$ \\
\hline
\end{tabular}




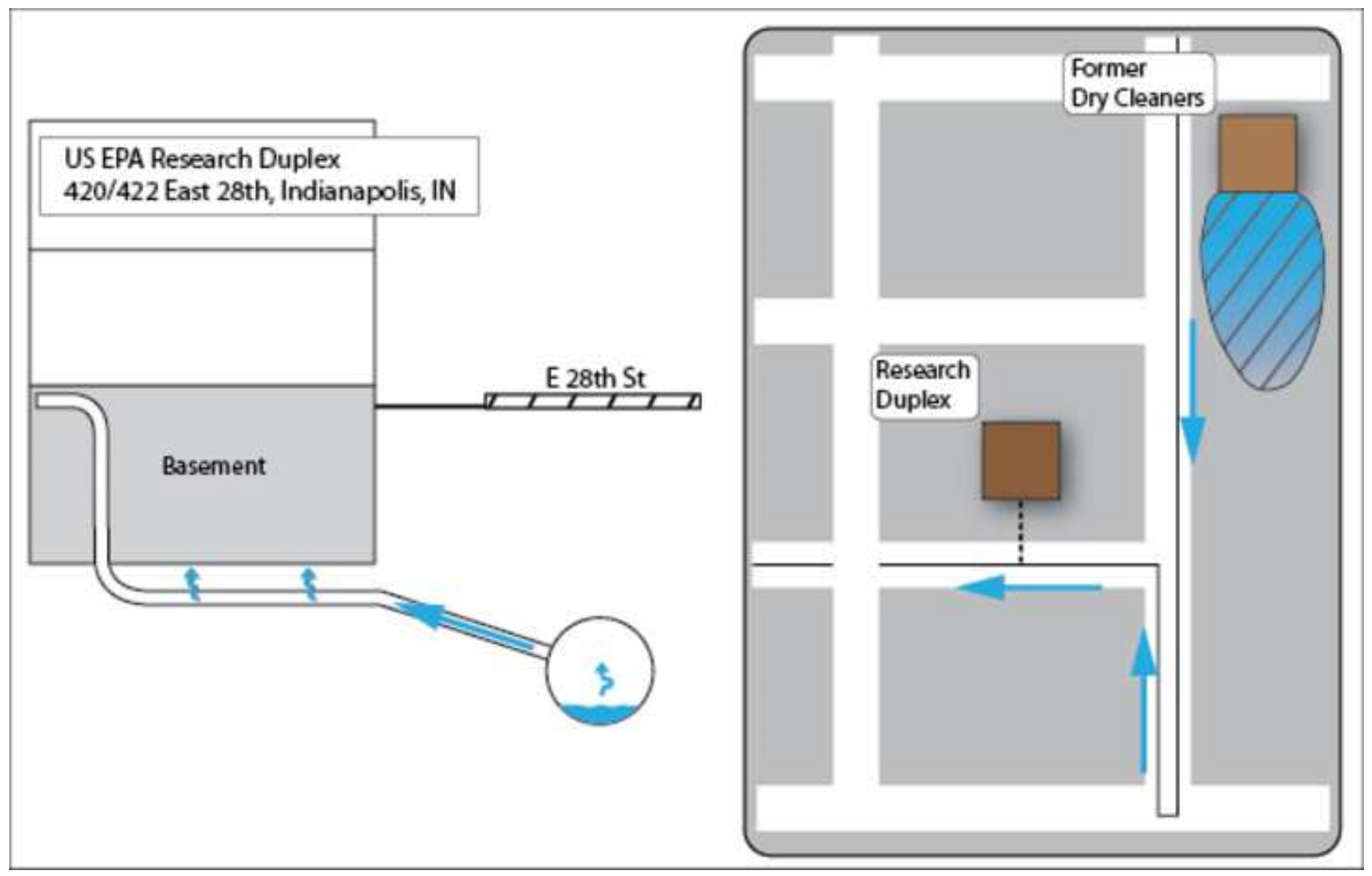

